\title{
Sepsis may dissimulate a lymphoma? Case report
}

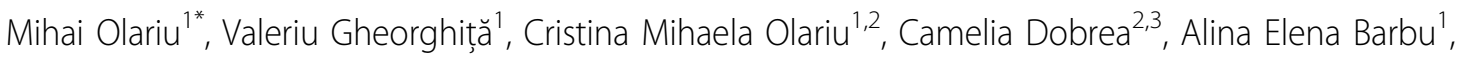 \\ Adriana Nurciu", Florin Căruntu ${ }^{1,2}$ \\ From The 10th Edition of the Scientific Days of the National Institute for Infectious Diseases "Prof Dr Matei \\ Bals" \\ Bucharest, Romania. 15-17 October 2014
}

\section{Background}

In aggressive lymphoma, systemic "B" symptoms of fatigue, fever, night sweats may occur frequently, but these symptoms may occur also in severe sepsis. Many hematological disorders, especially lymphoid neoplasms, have a high risk for infection because of altered humoral and cell-mediated immunity.

\section{Case report}

We present a case of a man 37 years old who was diagnosed in our clinic on July 2014 with diffuse large B-cell lymphoma. On July 5 the patient was admitted to the County Hospital Pitești with fatigue, fever, night sweats and epigastric pain. Laboratory evaluation remarks a severe pancytopenia but without inflammation marks and a positive procalcitonin.

Marrow aspiration sample showed 28\% lymphoid cells. The patient was transferred in our clinic with the diagnosis of sepsis. From family history we remark that his mother had died a few years back at 50 years old with acute leukemia. After clinical exam (pallor, splenomegaly), laboratory evaluation (severe pancytopenia: leukocytes $0.88 \times 10^{3} / \mu \mathrm{L}$, neutrophils $0.49 \times 10^{3} / \mu \mathrm{L}, \mathrm{Hb} 9.5 \mathrm{~g} / \mathrm{dL}$, platelets $25 \times 10^{3} / \mu \mathrm{L}$ ), LDH $1,704 \mathrm{IU} / \mathrm{L}$, prothrombin time $16.5 \mathrm{~s}$, fibrinogen $46 \mathrm{mg} / \mathrm{dL}$, partial thromboplastin time $56.9 \mathrm{~s}$, procalcitonin $3.95 \mathrm{ng} / \mathrm{mL}$ ), abdominal CT scan, we considered intra-abdominal sepsis and disseminated intravascular coagulation (DIC).

Treatment for 7 days with meronem $3 \mathrm{~g} /$ day, corticotherapy and supportive therapy, fresh frozen plasma, packed red blood cells, platelet concentrates did not ameliorate the clinical status and surgery exam disproved our suspicion. Because procalcitonin rose to $10.35 \mathrm{ng} / \mathrm{mL}$ treatment was completed with vancomycin $2 \mathrm{~g}$ /day, caspofungin $50 \mathrm{mg} /$ day, levofloxacin $1 \mathrm{~g} /$ day, amikacin $1 \mathrm{~g} /$ day and ethambutol $1 \mathrm{~g} /$ day and also we performed a bone marrow biopsy.

After 5 days procalcitonin was $1.57 \mathrm{ng} / \mathrm{mL}$ and the clinical status was ameliorated but pancytopenia persisted. The histopathological exam and the immunohistochemistry aspect sustained the diagnosis of diffuse large B-cell lymphoma and the patient was transferred to the Hematology Clinic.

\section{Conclusion}

In patients with severe infection who have a long evolution we must search for a hematological disease. Sometimes both hematological disease and sepsis may intertwine, being difficult to make a plain distinction.

\section{Consent}

Written informed consent was obtained from the patient for publication of this Case report and any accompanying images. A copy of the written consent is available for review by the Editor of this journal.

\section{Authors' details \\ ${ }^{1}$ National Institute for Infectious Diseases "Prof. Dr. Matei Balș", Bucharest, Romania. ${ }^{2}$ Carol Davila University of Medicine and Pharmacy, Bucharest, Romania. ${ }^{3}$ Fundeni Clinical Institute, Bucharest, Romania. ${ }^{4}$ University Emergency Hospital of Bucharest, Romania.}

Published: 15 October 2014

doi:10.1186/1471-2334-14-S7-P60

Cite this article as: Olariu et al:: Sepsis may dissimulate a lymphoma? Case report. BMC Infectious Diseases 2014 14(Suppl 7):P60.

\footnotetext{
* Correspondence: ol_mihai@yahoo.com

${ }^{1}$ National Institute for Infectious Diseases "Prof. Dr. Matei Balş", Bucharest, Romania

Full list of author information is available at the end of the article
} 